\title{
Recycling plastic: diagnosis and management of plastic bronchitis among adults
}

\author{
Prince Ntiamoah ${ }^{1}$, Sanjay Mukhopadhyay ${ }^{2}$, Subha $_{\text {Ghosh }}{ }^{3}$ and Atul C. Mehta ${ }^{1}$ \\ ${ }^{1}$ Dept of Pulmonary and Critical Care Medicine, Cleveland Clinic, Cleveland, OH, USA. ${ }^{2}$ Dept of Pathology, Cleveland Clinic, Cleveland, \\ $\mathrm{OH}$, USA. ${ }^{3}$ Diagnostic Radiology, Cleveland Clinic, Cleveland, OH, USA.
}

Corresponding author: Atul C. Mehta (MEHTAA1@ccf.org)

Shareable abstract (@ERSpublications)

Plastic bronchitis in adults is rare, heterogeneous in its aetiology, can lead to life-threatening emergencies and should not be overlooked. Lymphatic plastic bronchitis may be reserved for aetiologies that are secondary to lymphatic disruption. https://bit.ly/3c7RX00

Cite this article as: Ntiamoah P, Mukhopadhyay S, Ghosh S, et al. Recycling plastic: diagnosis and management of plastic bronchitis among adults. Eur Respir Rev 2021; 30: 210096 [DOI: 10.1183/ 16000617.0096-2021].

Copyright (The authors 2021

This version is distributed under the terms of the Creative Commons Attribution NonCommercial Licence 4.0. For commercial reproduction rights and permissions contact permissions@ersnet.org

Received: 14 April 2021 Accepted: 26 May 2021

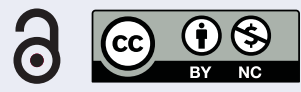

\section{Abstract}

Plastic bronchitis is a rare, underdiagnosed and potentially fatal condition. It is characterised by the formation and expectoration of branching gelatinous plugs that assume the shape of the airways. These airway plugs differ from the allergic mucin that characterises allergic bronchopulmonary aspergillosis and mucoid impaction of the bronchi. Plastic bronchitis is most often encountered in the paediatric population following corrective cardiac surgery, such as the Fontan procedure. It also occurs in adults. Plastic bronchitis in adults is rare, heterogeneous in its aetiology, and can lead to respiratory distress or even lifethreatening airway obstruction. Plastic bronchitis in adulthood should not be overlooked, particularly in patients with chronic inflammatory lung diseases. This review presents current understanding of the presentation, aetiology, pathogenesis, pathology and management of plastic bronchitis in adults.

\section{Introduction}

Plastic bronchitis is an extremely rare condition characterised by the formation and expectoration of cohesive bronchial casts which assume the shape of the local airways. Cast size ranges from a small segmental cast of one bronchus to a large tree-like cast filling the airways of an entire lung, potentially provoking fatal asphyxia (figure 1). Patients with plastic bronchitis may exhibit dyspnoea, wheezing, pleuritic chest pain or fever.

This condition differs from mucus plugging in its cohesiveness, consistency and difficult bronchoscopic removal. The initial description of the condition has been credited to GALEN (AD 131-200) who erroneously described this phenomenon as venae arteriosae expectorate, identifying the casts as expectorated blood vessels [1]. Subsequent case reports and case series have confirmed the existence of this entity. However, numerous descriptors, some of which are discrete entities, have been used for plastic bronchitis, including pseudomembranous bronchitis, mucoid impaction, cast bronchitis, fibrinous bronchitis, bronchitis fibroplastica and Hoffman bronchitis [2]. In 1750, Bussiene reported a post mortem examination of a patient who was thought to have tuberculosis but was found to have a bronchial cast in situ [3].

Regardless of the nomenclature, the aetiology behind the formation of these casts has important therapeutic consequences. Although some commonalities exist, it is likely that the aetiology of plastic bronchitis is heterogeneous. Thus, understanding of the pathogenesis of plastic bronchitis remains limited.

This review presents the current understanding of the clinical presentation, aetiology and management of plastic bronchitis. Adult plastic bronchitis is illustrated with two case reports. 


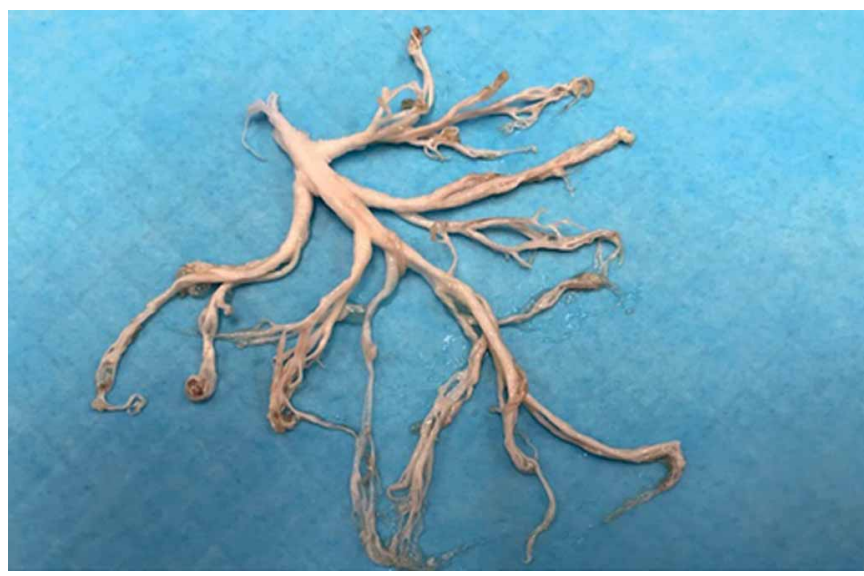

FIGURE 1 Pathological appearance of plastic bronchitis. Macroscopic tree-like appearance is a perfect cast of the bronchial tree.

\section{Case 1}

A 42-year-old male never-smoker was admitted with dyspnoea, productive cough and a 16-pound weight gain. His history was notable for heart failure with preserved ejection fraction and hypertrophic obstructive cardiomyopathy. Echocardiography confirmed severe septal hypertrophy. Characteristic clinical signs supported the premise that Noonan syndrome was the cause of his cardiomyopathy.

His cough was productive of 2-3 cm rubbery mucus threads. He reported that the expectoration occurred every 2 weeks, had been ongoing for the past 9 months and was associated with progressively worsening dyspnoea. Despite treatment with diuretics his cough persisted.

Computed tomography (CT) of the chest revealed clustered tiny centrilobular nodules and peribronchial ground-glass opacities in both lungs, involving the right lower lobe, middle lobe and the superior segment of the left lower lobe. Treatment with multiple courses of antibiotics yielded no response.

Pathologic examination of the cast revealed a predominance of fibrin, with a small amount of mucin and few inflammatory cells (figure 2e). The inflammatory cells included lymphocytes and scattered foamy macrophages. A lymphangiogram revealed an abnormal lymphatic drainage pattern with a large duct coursing to the right hilar region and terminating in small peribronchial lymphatics (figure 3). Embolisation of the thoracic duct was performed, with no recurrence of cast production. The patient's repeated subsequent admissions for decompensated heart failure warrant the consideration of surgical correction of his hypertrophic cardiomyopathy.

\section{Case 2}

A 41-year-old female presented with a history of repeated episodes of left lung collapse. Her medical history was notable only for a parvovirus infection during pregnancy and a partial thyroidectomy for a goiter. She had been healthy up to 18 months prior to her initial presentation of left lung collapse. She had another episode 4 months later that was characterised by dry cough, subsequent yellow mucus production and fevers as high as $40^{\circ} \mathrm{C}$. She presented to a local hospital with acute respiratory distress and hypoxic respiratory failure and received emergent intubation.

She reported no occupational exposures and was a lifelong nonsmoker. Family history was notable for asthma in her mother and brother, lung cancer in her sister and hypertension in both her parents.

Flexible bronchoscopy revealed and removed a bronchial cast involving the left main stem bronchus. She was treated with 5 days of intravenous antibiotic therapy prior to being discharged. The patient continued to experience episodes of pneumonia symptoms with radiographic signs of left lower lobe collapse. She also complained of palpitations. She was treated with short-acting beta-agonist bronchodilators and multiple courses of oral antibiotics without significant improvement. She underwent four flexible bronchoscopies, each revealing bronchial casts in addition to excessive dynamic airway collapse and circumferential narrowing of the left main stem bronchus. 

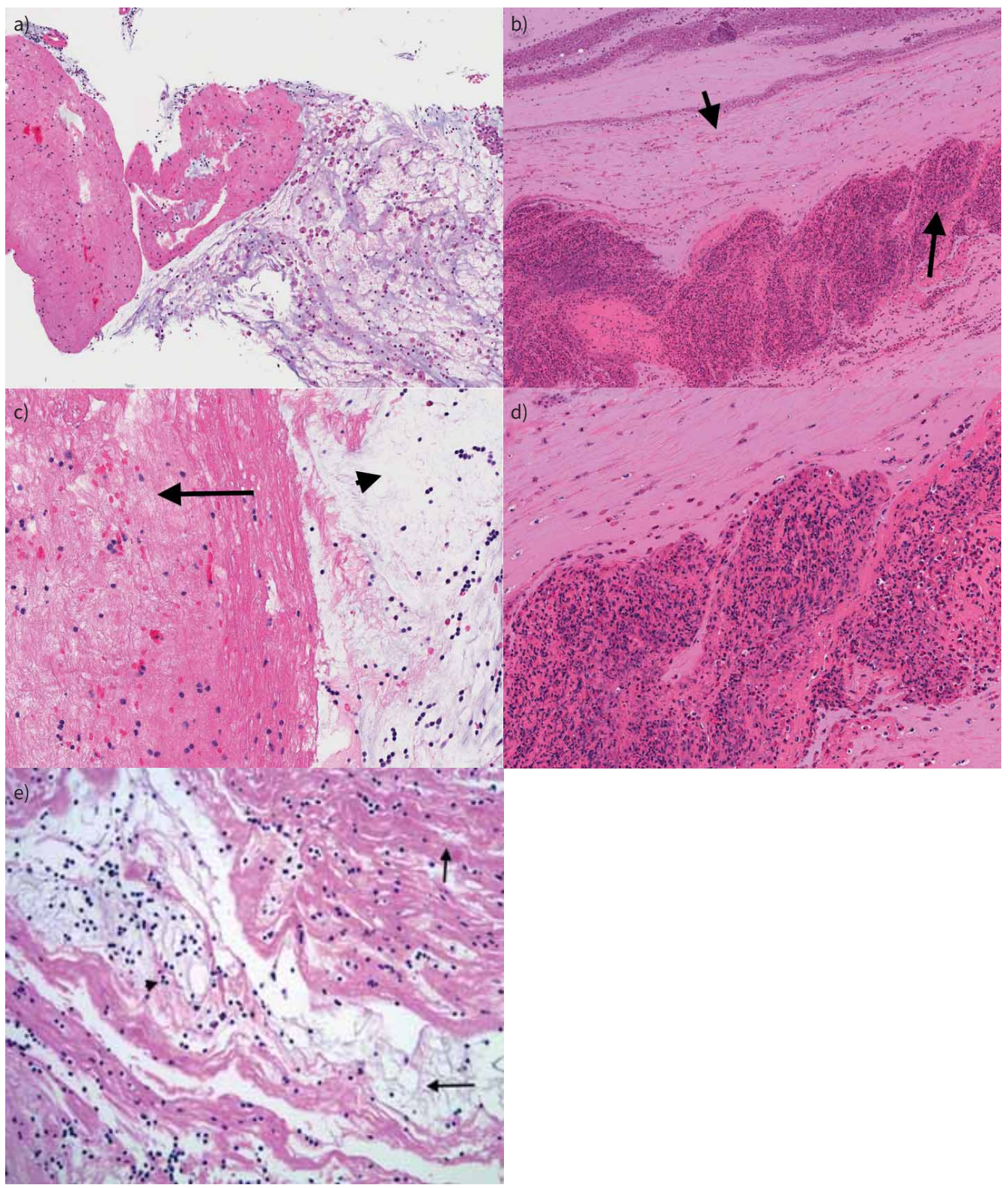

FIGURE 2 Plastic bronchitis versus allergic bronchopulmonary aspergillosis/mucoid impaction of bronchi. a) Plastic bronchitis, low magnification. No lamellated appearance. Fibrin on the left; mucin on the right. b) Mucoid impaction of bronchi (allergic mucin) at low magnification. Lamellated appearance is apparent. The lighter areas (short arrow) contain mucin, while the darker areas (long arrow) contain debris with innumerable degenerating eosinophils. c) Plastic bronchitis, high magnification. Fibrin (arrow), mucin (arrowhead) and a few lymphocytes. No eosinophils. d) Mucoid impaction of bronchi (allergic mucin) at high magnification. A large number of degenerating eosinophils are present. e) Microscopic appearance of cast from case 1 . The cast is a mix of fibrin (short arrow), mucin (long arrow) and lymphocytes (arrowhead). Haematoxylin-eosin stain, original magnification $\times 200$.

At presentation to our institution, her chest CT demonstrated circumferential narrowing of the left main stem bronchus with excessive dynamic airway collapse on free breathing images. It also demonstrated bronchial casts in the right lower lobe. A lymphangiogram demonstrated no evidence of extravasation or reflux into the hilar or pulmonary lymphatics. Bronchoscopy confirmed 50\% occlusion of the left main stem bronchus. A tubular branching opacity with increased attenuation compatible with a bronchial cast containing inspissated, desiccated material was noted in the right lower lobe. 

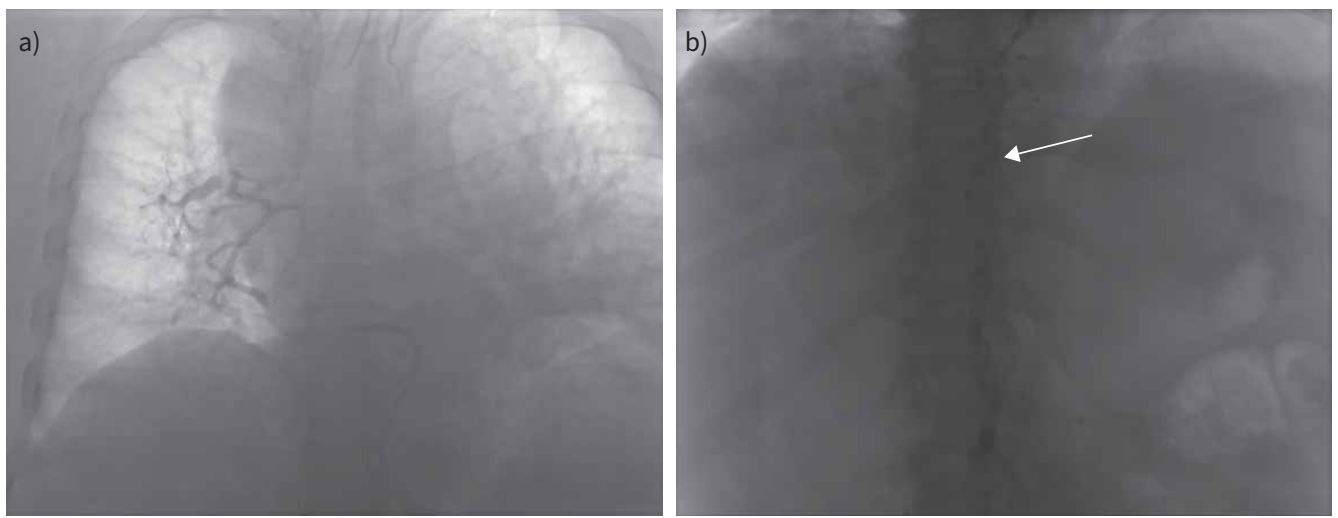

FIGURE 3 a) and b) Lymphangiograms show abnormal thoracic lymphatic drainage patterns with a large duct (white arrow in b) that courses into the right hilar region and terminates in small peri-bronchial lymphatics.

The patient was referred to cardiology for her palpitations and was noted to have no structural abnormalities on echocardiography. Holter monitoring demonstrated that the most symptomatic episodes of dyspnoea and palpitations were related to sinus tachycardia with ventricular ectopic beats. She was switched to diltiazem and ivabradine due to intolerance to bisoprolol. Heart rate control was achieved, and the patient did not have symptoms during 2.5 months of observation. It remains uncertain if an underlying structural airway abnormality combined with underlying cardiac dysfunction led to cast formation.

\section{Epidemiology}

No specific epidemiological studies of adult plastic bronchitis have been performed. The literature is derived from case series and case reports of this rare condition. A slight male predominance is noted in all categories except asthma and other allergic causes [4, 5], for which female predominance is noted in one report [6]. Incidence and prevalence cannot be accurately determined because it is likely that the condition is under recognised.

\section{Clinical features}

Patients may be asymptomatic or may present with dyspnoea, wheezing, chest discomfort and fever. Patients may have a history of expectoration of casts in the shape of the airways. In the 1950s, a patient expectorated spherical globules that assumed dendritic forms when placed in water [7, 8]. Patients may have a history of antecedent viral infections, specifically influenza A infection [9, 10].

Breath sounds may be diminished or absent due to the casts that obstruct or occupy the airway. A focal wheeze may also be heard [11]. A number of characteristic physical examination findings have been reported. The bruit de pot felé (cracked pot sound) is a metallic sound noted on percussion in a focal area [8]. A peculiar flapping or clicking sound has been observed just prior to the expectoration of casts, described as bruit de drapeau (flag sound) or Ventilgeräusch (valve sound). These are thought to be sounds of the mucus plug impacting the airway wall $[1,9,12]$. However, a more common finding may be diminished breath sounds.

\section{Radiology}

Chest radiography or CT may demonstrate endoluminal obstruction of the airways and extensive atelectasis in the involved lung segment with compensatory hyperinflation [7, 12].

Other studies have reported patients with bilateral patchy consolidations without evidence of volume loss. Radiologic findings are generally nonspecific, thus the diagnosis of plastic bronchitis must be confirmed by observation of casts. However, diagnostic lymphangiography may be useful in specific contexts which are discussed below.

\section{Bronchoscopy}

Bronchoscopy may facilitate the extraction of thick, rubbery, tenacious mucus casts that assume the shape of the airways [7, 11, 13]. 
Aetiology of cast formation

Several aetiologies and disease associations with plastic bronchitis and cast formation have been reported. These include primary or secondary lymphatic abnormalities, viral infections, bacterial infections, haematological conditions, occupational exposures, malignancy and others. It is a matter of debate as to which of these can truly be considered plastic bronchitis (table 1) [14].

\section{Primary or secondary lymphatic abnormalities}

Primary lymphatic abnormalities such as lymphangiectasis and lymphangiomatosis can contribute to chyle leakage and may lead to plastic bronchitis. One case report involved a 49-year-old female who underwent a lobectomy for recurrent cast formation. Pathological examination demonstrated fibrosis and dilated lymphatic vessels at the hilum. A similar case was described of a 25-year-old male with lymphangiomatosis characterised by dilated proliferative lymphatic channels which resolved after thoracic duct ligation [15, 16].

Reports of plastic bronchitis are most common in the paediatric literature and are secondary to palliative single ventricle operations such as the Fontan, Glenn and Blalock-Taussig procedures. Post-operatively, some patients develop plastic bronchitis which may arise from aberrant lymphatic drainage and decompensated heart failure. Whether these lymphatic abnormalities are primary or secondary remains unclear $[17,18]$.

\section{Viral infections}

Influenza and adenovirus infections have been described as aetiologies for plastic bronchitis in children. These paediatric presentations suggest the possibility that influenza and an underlying predisposition might rarely produce plastic bronchitis in adults. Full genome sequencing of the virus in two reported cases did not reveal evidence of specific virulent mutations, which suggests a host factor $[9,19,20]$.

A bloody cast formation was described in an adult with an influenza infection. Pathologic examination confirmed a blood clot. Whether this adult case requiring veno-venous extracorporeal membrane oxygenation (ECMO) and anticoagulation was secondary to airway haemorrhage and clot formation leading to cast formation, or was due to another underlying pathology is unclear. Influenza infection remains a possible but uncertain aetiology of adult bronchitis.

\section{Bacterial infections}

Two cases have been reported of plastic bronchitis in children with cystic fibrosis. Because cystic fibrosis patients now frequently survive to adult age, the roles of bacterial pathology and other underlying predispositions to cast formation must be considered [21, 22].

TABLE 1 Aetiology of cast formation

\begin{tabular}{|c|c|}
\hline Aetiology & Disease association \\
\hline $\begin{array}{l}\text { Primary or secondary lymphatic } \\
\text { abnormalities }\end{array}$ & $\begin{array}{l}\text { Congenital heart disease with surgical repair (Fontan, Glenn, Blalock- } \\
\text { Taussig procedures) } \\
\text { Lymphatic abnormalities, lymphangiectasia, lymphangiomatosis }\end{array}$ \\
\hline Viral infections & $\begin{array}{l}\text { Influenza A infection } \\
\text { Adenovirus infection } \\
\text { Rhinovirus infection } \\
\text { Respiratory syncytial virus infection } \\
\text { Parainfluenza virus infection }\end{array}$ \\
\hline Bacterial infectious processes & $\begin{array}{l}\text { Streptococcus spp., Haemophilus spp., Mycobacterium tuberculosis, } \\
\text { Klebsiella spp. } \\
\text { Cystic fibrosis }\end{array}$ \\
\hline Haematologic conditions & Sickle cell acute chest syndrome \\
\hline Occupational exposure & Silicosis \\
\hline Malignancy & $\begin{array}{l}\text { Kaposi sarcoma with possible involvement of lymphatics } \\
\text { Endobronchial renal cell metastasis }\end{array}$ \\
\hline Miscellaneous & $\begin{array}{l}\text { Post tracheoesophageal fistula repair, in the setting of biological mesh } \\
\text { repair of fistulae and superinfection post-operatively } \\
\text { Post coronary artery bypass grafting } \\
\text { Post lung transplant with primary graft dysfunction } \\
\text { Heart failure post mantle field radiation for lymphoma } \\
\text { Primary graft dysfunction post bilateral lung transplantation } \\
\text { Inhalational injury by sulfur mustard analogue in animal models }\end{array}$ \\
\hline
\end{tabular}


Case reports of cast specimens and various bacterial isolates on histopathological examination exist but are infrequent and predate current antibiotic therapy and standards of care which makes it difficult to describe these cases as plastic bronchitis [7].

\section{Haematological conditions}

Sickle cell acute chest syndrome has been well described in a paediatric series of 21 patients with plastic bronchitis [23]. A similar presentation is described in a 19-year-old patient with sickle cell acute chest syndrome; however, the underlying pathophysiology remains unknown [24].

\section{Occupational exposure}

Silicosis, a pneumoconiosis caused by occupational exposure to airborne silica particles, induces fibrotic changes in the thoracic lymph nodes [25]. Two cases of silicosis leading to plastic bronchitis have been reported, one of which was thought to be secondary to pulmonary venous occlusion. However, the lymph node involvement of silicosis raises the possibility of lymphatic disruption [26, 27].

\section{Malignancy}

Cast formation in a patient with pulmonary Kaposi sarcoma, a vascular malignancy that can involve lymphatic endothelium has been reported [28]. Plastic bronchitis was described in a 67-year-old male after tumour debulking and radiation treatment of endobronchial renal cell metastasis [29].

\section{Miscellaneous conditions}

Iatrogenic causes of cast formation such as radiation or surgical trauma leading to probable lymphatic disruption have also been reported [23, 30, 31]. Plastic bronchitis has also been reported in a post-lung transplant patient with primary graft dysfunction on ECMO. The patient had a history of whole-body radiation and had possibly developed coagulopathy, therefore multiple sequelae including bleeding and lymphatic disruption could have caused cast formation [32]. Another case of plastic bronchitis in an adult lung transplant patient with refractory donor-related asthma has also been reported [33].

Although the aetiology for adult plastic bronchitis remains incompletely elucidated, a common theme appears to be impairment of lymphatic drainage, from infection, inflammation or trauma.

\section{Cast pathology and classification}

The pathology of casts and its role in classification has evolved significantly. Terms such as type I and type II casts are no longer widely used. The classic pathologic appearance of the casts of plastic bronchitis is shown in figure 1. The histological appearance is consistent with lymphatic obstruction. These casts contain fibrin, mucin and a few lymphocytes and macrophages, which suggests a mix of lymph (chyle) and bronchial mucus. The casts of plastic bronchitis must be differentiated from other distinctive causes of bronchial casts, namely allergic bronchopulmonary aspergillosis and the related entity mucoid impaction of bronchi (MIB), which are characterised by a lamellated appearance at low magnification (figure 3). At high magnification, these casts contain large numbers of degenerating eosinophils and Charcot-Leyden crystals, which are distinct from the casts of plastic bronchitis.

\section{Casts in structural heart diseases}

Structural heart disease causing cast formation is chiefly a paediatric entity. It is also a possible mechanism in adults. Plastic bronchitis pathology has been classified based on the presence or absence of structural heart disease. This classification utilises a retrospective amalgamation of case reports, and some questions persist regarding the composition and pathogenesis of casts in structural heart diseases [14]. A more recent prospective study involving five children with congenital heart disease with plastic bronchitis sought to elucidate cast histology. The majority of these patients had undergone Fontan palliation. All studied casts contained fibrin with some lymphocytic and mononuclear cell infiltration. A small amount of mucin was noted in some, but not all casts, suggesting that fibrin accumulation predominates in patients with underlying congenital heart disease [34]. The exact composition of casts is unclear due to the limited number of cases that can be studied prospectively. However, several case reports document the presence of fibrin and mucin within the casts [35-37].

More recent data suggest that cast formation in patients with underlying structural heart disease is often accompanied by lymphatic abnormalities. T2-weighted magnetic resonance imaging (MRI) lymphangiography has demonstrated that patients with plastic bronchitis and protein-losing enteropathy in the setting of structural heart disease had lymphatic abnormalities in a blinded retrospective study [38]. Optimal management of cardiac failure and percutaneous embolisation of aberrant lymphatics often reduces cast formation. 
Thoracic duct ligation has been reported as a successful therapeutic intervention in children with underlying structural heart disease [15]. It has been proposed that high central venous pressure leads to increased lymphatic production and decreased lymphatic drainage at the thoracic duct outlet of the innominate vein. This process can lead to lymphatic dilatation and collaterals, lymph accumulation within the airways and eventual cast formation. Notably, the same group of authors performed a subsequent retrospective review of MRI data and identified several patterns of lymphatic abnormalities in patients after Fontan palliation. Interestingly, the patients with plastic bronchitis had a pattern of abnormal lymphatics extending into the lung parenchyma, also described as pulmonary lymphatic perfusion syndrome [7, 39].

While lymphatic abnormalities are strongly associated with plastic bronchitis, it is uncertain whether lymphatic leakage can be the sole cause of the cast formation. Proteomics analysis of casts in Fontan patients demonstrated endogenous fibrinolytics and aberrant fibrin deposition within the casts. It has been proposed that a dysregulated inflammatory response and unresolved inflammation may create a milieu of aberrant fibrin deposition and subsequent cast formation. These data must be interpreted cautiously as it is a single centre, limited series confined to one population of patients. However, subsequent studies of cast proteomics may elucidate why cast formation is seen in a variety of underlying pathologies [40].

\section{Casts unrelated to structural heart disease}

Lymphatic abnormalities

Patients with underlying primary lymphatic abnormalities can develop plastic bronchitis with chylous casts. Lymphatic abnormalities may occur in underlying structural heart disease, but whether these are primary is unclear. Primary lymphatic abnormalities can occur in congenital syndromes (yellow nail syndrome, Noonan syndrome, etc.) or lymphangiomatosis [14, 17, 18]. While some patients develop chyloptysis without developing plastic bronchitis, lymphatic leakage into the airways has been strongly associated with plastic bronchitis [41, 42].

\section{Atopic disease and eosinophilic casts}

The literature frequently mentions asthma, atopy and allergic bronchopulmonary aspergillosis as possible aetiologies of plastic bronchitis, but this is an erroneous premise [7, 14, 43]. Casts resulting from these conditions contain innumerable eosinophils and Charcot-Leyden crystals and thus are aetiologically related to asthma or fungal hypersensitivity phenomena. It is unclear why some patients with underlying asthma or related illnesses develop mucoid impaction severe enough to form casts. The secretory hyperresponsiveness and goblet cell hyperplasia known to occur in asthma may be contributory factors [44].

Casts in acute chest syndrome with sickle cell disease

The largest series of plastic bronchitis in acute chest syndrome has been described in a paediatric population [45] The cast pathology was notable for yellowish bronchoalveolar lavage fluid, fibrinous material and pigmented histiocytes. Respiratory tract pathogens were isolated in several patients in this series, and it is possible that infection may foster cast formation. Increased pulmonary blood volume and airway ischemia due to vaso-occlusion and the resultant impairment in mucociliary clearance may also facilitate cast formation. The chest pain and inability to expectorate associated with splinting may be additional factors in cast formation in sickle cell disease [24, 45].

Casts associated with infectious aetiologies

Several reports propose an infectious trigger for cast formation, especially in children with influenza. This association is not well established in adults. The report of adult plastic bronchitis in the setting of influenza A may have been related to haemorrhage rather than viral infection [10].

A minority of children with influenza have developed plastic bronchitis with compatible pathology, raising the possibility of an underlying, perhaps lymphatic predisposition [9, 10, 46].

Sparse reports note bacterial infections and cystic fibrosis leading to cast formation. Early case reports mention the isolation of respiratory pathogens, in addition to inflammatory cells within casts. Whether these organisms were pathogenic or colonising is uncertain. These may represent extremes of mucoid impaction or simply cast formation due to another predisposing cause. However, current medical care, antibiotic therapy and the relative rarity of these reports preclude the conclusion that bacterial infection is a true aetiology of cast formation.

\section{Treatment}

The most important step in the treatment of plastic bronchitis is to identify the underlying aetiology (figure 4). 


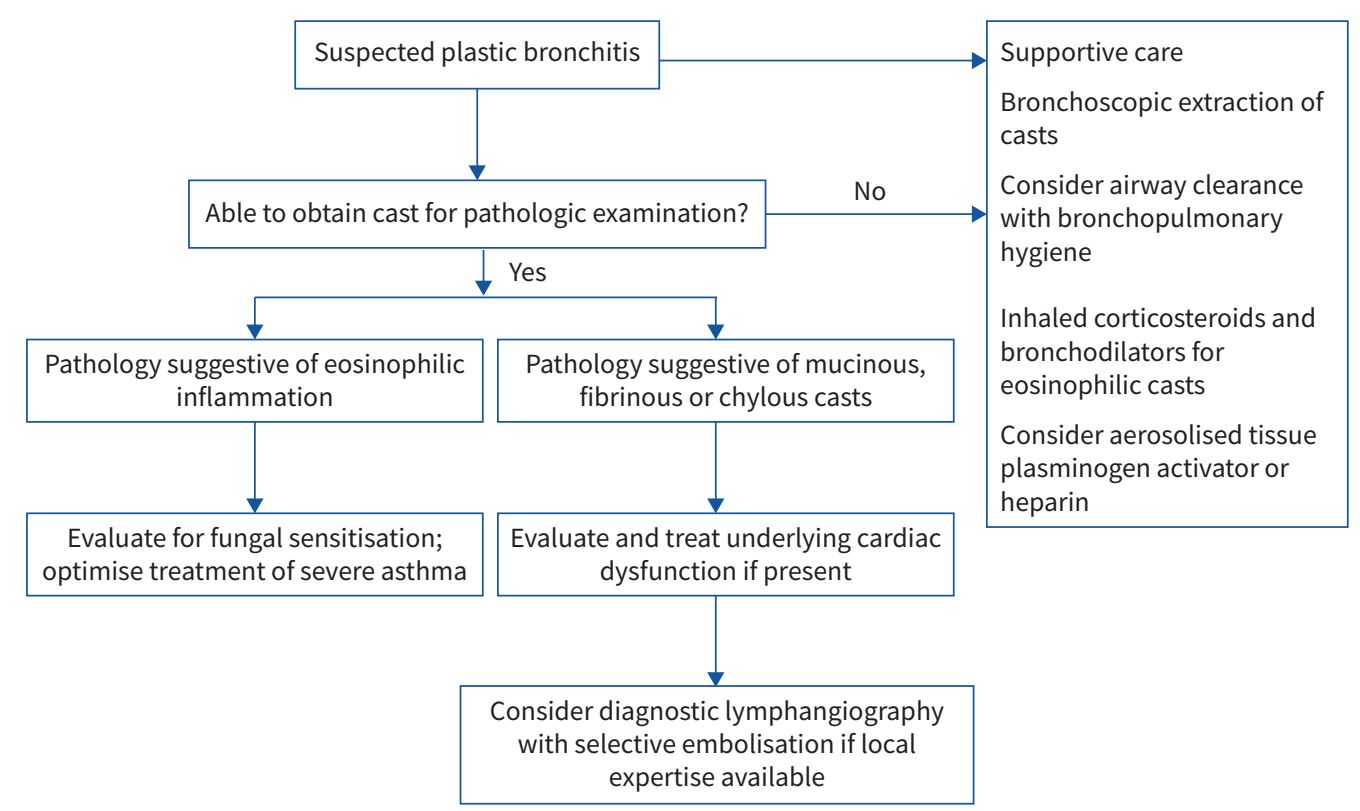

FIGURE 4 Suggested algorithm for diagnosis and management of plastic bronchitis.

Supportive care and bronchoscopic management

First, underlying respiratory failure must be treated. If hypoxaemia and airway obstruction are severe, endotracheal intubation with emergent bronchoscopy can relieve airway obstruction. Bronchoscopy and the use of cryoextraction can facilitate the safe removal of casts [47, 48].

ECMO may be necessary to support the patient during the process of relieving airway obstruction [49]. In patients with life-threatening progressive respiratory failure, in whom significant cast obstruction may progress to cardiorespiratory collapse, prompt therapy with ECMO as a clinical adjunct may be effective and lifesaving.

Once removed, the casts should be carefully collected and sent for pathological examination. Cast histology and bronchoalveolar lavage fluid cultures can reveal important details about infection and inflammatory pathology, such as asthma, or a primary or secondary lymphatic disorder.

Of note, high-frequency jet ventilation has been used successfully in two paediatric plastic bronchitis cases where bronchoscopy was not immediately available [50]. This was used as a short-term adjuvant therapy because urgent bronchoscopy was considered a high-risk procedure for the first patient and was not available for the second patient. The authors concluded that high frequency jet oscillation can be employed as a rescue therapy for the rare patient in whom bronchoscopy is considered a high risk procedure or is unavailable. Consideration can also be given to cough-assist devices as alternatives to high-frequency jet ventilation.The use of rigid bronchoscopy (RB) in adult PB literature is rare. All the current literature is in the paediatric population. The ability of RB to provide a larger conduit for therapeutic manoeuvres may be an added benefit. There may be an adjunctive role for serial RB in adult patients with recurrent symptoms who are unresponsive to current therapy.

\section{Inhaled corticosteroids, hypertonic saline and airway clearance}

Conservative medical management reports are chiefly anecdotal. Hypertonic saline, bronchodilators, mucolytics, expectorants, inhaled corticosteroids, chest physiotherapy and mechanical airway clearance devices may or may not provide acute or chronic relief from cast expectoration but are unlikely to cause harm [51]. Importantly, inhaled bronchodilator and corticosteroid therapy could be vital if the casts are eosinophilic and the patient has uncontrolled asthma.

\section{Aerosolised tissue plasminogen activator and heparin}

Inhaled tissue plasminogen activator (tPA) can be considered as an option, especially in patients who cannot immediately undergo bronchoscopy. Aerosolised tissue plasminogen activator has been shown to reduce cast mass ex-vivo [34]. Several case reports have demonstrated its successful use. A trial of 

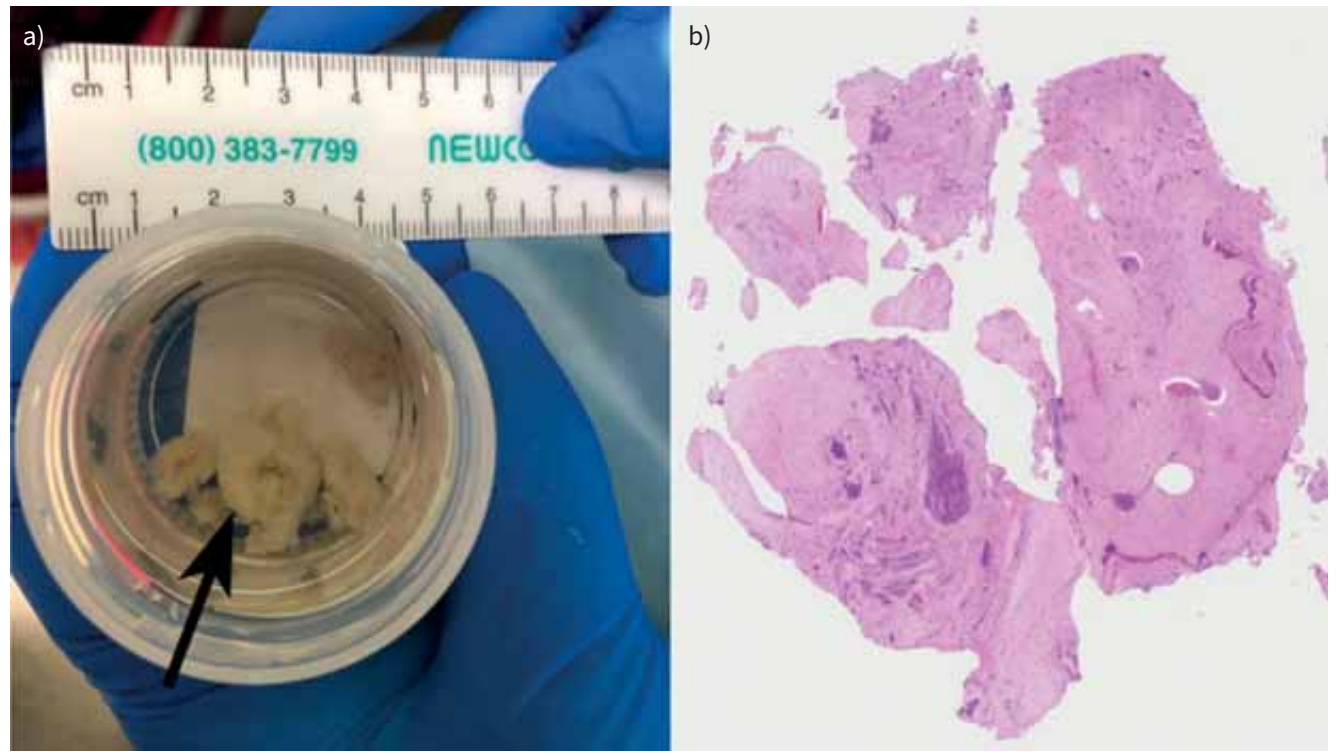

FIGURE 5 Macroscopic appearance of material removed from endotracheal tube. a) Cylindrical fragments of mucus-like material (arrow) seen in this formalin jar. b) The same material is shown at very low magnification (haematoxylin-eosin stain; 0.6× magnification).

nebulised tPA at a dose of $0.7-1 \mathrm{mg} \cdot \mathrm{kg}^{-1}$ every 4 hours may be considered, depending on the clinical situation [51, 52]. Therapeutic bronchoscopy with topical tPA at a total dose of $3.5 \mathrm{mg}$ in $0.5 \mathrm{mg}$ aliquots has also been reported in a paediatric case [53]. It is likely that tPA effectiveness is predicated on the fibrin content of the casts and may not be a useful intervention in the setting of asthma or a related aetiology.

Aerosolised heparin has also been used with success in a paediatric case at a dose of 5000 units every 4 hours or at a dose of 155 units $\cdot \mathrm{kg}^{-1} \cdot$ dose $^{-1}$ twice daily. It is unclear whether the effects of heparin are due to anti-inflammatory properties or its effects on thrombolysis via antithrombin III [54, 55]. Heparin is a less expensive option and may be less irritating to the airways than tPA [51].

\section{Advanced lymphatic imaging and percutaneous selective embolisation}

Dynamic contrast-enhanced magnetic resonance lymphangiography (DCMRL) and intranodal lymphangiography have been used to demonstrate aberrant pulmonary lymphatic flow as a cause of plastic bronchitis in adults and paediatric patients $[38,56]$.

In one study, selective embolisation of abnormal lymphatics with glue and coils was performed with successful results in all patients, with a mean follow-up of 11 months [56]. It was reported that percutaneous transabdominal catheterisation and embolisation of the pulmonary lymphatics is a safe and effective treatment for the acute manifestation of this disorder, but additional studies are needed to determine the long-term safety and durability of this approach.

In addition to infection, bleeding and inadvertent puncture, which are inherent risks of percutaneous procedures, rare cases of cerebral embolisation of ethiodised oil have been reported with intranodal lymphangiography [57].

Complete occlusion of the thoracic duct is an option when targeting smaller vessels is impractical or unsuccessful $[15,58]$.

\section{Macrolide antibiotics}

Macrolide antibiotics have anti-inflammatory and immunomodulatory effects in chronic respiratory illnesses [59]. Case reports of effective macrolide use suggest utility in plastic bronchitis. However, one report which used macrolides successfully for long-term control was in a paediatric case with sensitivity to multiple fungi, suggesting an aetiology such as allergic bronchopulmonary mycosis [60]. While macrolides may be useful in such underlying inflammatory states, they may not be useful in lymphatic aetiologies. 
Inhibitors of the mechanistic target of rapamycin pathway

Sirolimus, an inhibitor of the mechanistic target of rapamycin (mTOR) pathway, has successfully treated recurrent chylothorax in lymphangioleiomyomatosis (LAM) [61]. Sirolimus was successfully used in one adult patient refractory to all other therapy, with demonstrated lymphatic abnormalities on lymphoscintigraphy and when percutaneous embolisation was not available. Sirolimus may be a treatment option for patients with chronic disease unable to receive other therapy. A dose of 1-2 mg daily, targeting a therapeutic trough of $5-10 \mathrm{ng} \cdot \mathrm{mL}^{-1}$, may be considered. Adverse drug reactions of sirolimus include stomatitis, diarrhoea, hypertriglyceridemia, pneumonitis, haematological abnormalities, renal insufficiency, among others [15].

\section{Improvement of cardiac function}

In paediatric patients, treatment of underlying cardiac disease should be the first priority.

In adult patients, treatment may include the use of pulmonary vasodilator therapy, beta blockers, heart transplantation or surgical modification of existing shunt procedures such as takedown or fenestration [4].

\section{Conclusion}

The true prevalence of plastic bronchitis among adults is unknown because many patients with mild forms of the disease remain undiagnosed. All pulmonologists should be aware of its presentation among adults. The current hypothesis regarding the common final pathogenic pathway is that numerous stimuli lead to lymphatic drainage obstruction, which result in an airway accumulation of chyle and mucin.

In the era of COVID-19, severely ill patients who require prolonged mechanical ventilation have been found to have thick, viscous material stuck firmly to the inner wall of the endotracheal tube (figure 5), consisting primarily of mucin and cellular debris [62]. Whether there is any relationship with plastic bronchitis remains to be studied. Whether lymphatics are involved in COVID-19 remains to be seen.

The term plastic bronchitis or lymphatic plastic bronchitis may be reserved for aetiologies that are secondary to lymphatic disruption. Optimal therapies for plastic bronchitis remain limited, with treatment varying with presentation and underlying aetiology. Airway clearance, using standard chest physiotherapy and/or bronchoscopy, is among the most-utilised therapies in the treatment of plastic bronchitis. Selective lymphatic embolisation at centres with appropriate interventional expertise offers a potential new treatment option for patients with plastic bronchitis. Other causes of cast formation include severe asthma (including allergic bronchopulmonary aspergillosis and/or MIB), viral infection and bleeding, which may be independent of lymphatic aberration. The underlying cause must be carefully identified and treated with a low threshold for consideration of lymphatic pathology.

Provenance: Submitted article, peer reviewed.

Conflict of interest: None declared.

\section{References}

$1 \quad$ Bettmann M. Report of a case of fibrinous bronchitis, with a review of all cases in the literature. Am J Med Sci 1902; 123: 304-329.

2 Panchabhai TS, Mukhopadhyay S, Sehgal S, et al. Plugs of the air passages: a clinicopathologic review. Chest 2016; 150: 1141-1157.

3 Callahan JA. Fibrinous bronchitis: report of case. J Am Med Assoc 1951; 147: 313-316.

4 Avitabile CM, Goldberg DJ, Dodds K, et al. A multifaceted approach to the management of plastic bronchitis after cavopulmonary palliation. Ann Thorac Surg 2014; 98: 634-640.

5 Sung C, Bass JL, Berry JM, et al. The thoracic duct and the Fontan patient. Echocardiography 2017; 34: 1347-1352.

6 Levine C. Primary disorders of the lymphatic vessels - a unified concept. J Pediatr Surg 1989; 24: 233-240.

7 Jett JR, Tazelaar HD, Keim LW, et al. Plastic bronchitis: an old disease revisited. Mayo Clin Proc 1991; 66: 305-311.

8 Oliver T. Remarks on plastic or croupous bronchitis. Br Med J 1899; 2: 69-72.

9 Uda K, Shoji K, Koyama-Wakai C, et al.. Clinical characteristics of influenza virus-induced lower respiratory infection during the 2015 to 2016 season. J Infect Chemother 2018; 24: 407-413.

10 Okada Y, Okada A, Narumiya $\mathrm{H}$, et al. Bloody bronchial cast formation due to alveolar hemorrhage associated with H1N1 influenza infection. Intern Med 2017; 56: 2747-2751.

11 Johnson RS, Sita-Lumsden EG. Plastic bronchitis. Thorax 1960; 15: 325-332. 
12 Liston SL, Porto D, Siegel LG. Plastic bronchitis. Laryngoscope 1986; 96: 1347-1351.

13 Fairshter RD, Riley CA, Hewlett RI. Large bronchial casts. Arch Intern Med 1979; 139: 522-525.

14 Madsen P, Shah SA, Rubin BK. Plastic bronchitis: new insights and a classification scheme. Paediatr Respir Rev 2005; 6: 292-300.

15 Shah A, Donavan J, Marino P, et al.. A lesson in plasticity: a 74-year-old man with plastic bronchitis. Thorax 2017; 72: 1055-1077.

16 El Mouhadi S, Taillé C, Cazes A. et al. Plastic bronchitis related to idiopathic thoracic lymphangiectasia: noncontrast magnetic resonance lymphography. Am J Respir Crit Care Med 2015; 192: 632-633.

17 Languepin J, Scheinmann P, Mahut B, et al. Bronchial casts in children with cardiopathies: the role of pulmonary lymphatic abnormalities. Pediatr Pulmonol 1999; 28: 329-336.

18 Blanco Pérez JJ, Arnalich Montiel V, Guerra Vales JL. Plastic bronchitis in a patient with silicosis. Arch Bronconeumol 2017; 53: 516

19 Lu Z, Zheng Y. Plastic bronchitis associated with adenovirus infection. Lancet Infect Dis 2018; 18: 474.

20 Deng J, Zheng Y, Li C, et al. Plastic bronchitis in three children associated with 2009 influenza A(H1N1) virus infection. Chest 2010; 138: 1486-1488.

21 Salamone I, Mondello B, Lucanto MC, et al. Bronchial tree-shaped mucous plug in cystic fibrosis: imaging-guided management. Respirol Case Rep 2017; 5: 214.

22 Mateos-Corral D, Cutz E, Solomon M, et al. Plastic bronchitis as an unusual cause of mucus plugging in cystic fibrosis. Pediatr Pulmonol 2009; 44: 939-940.

23 Garcia-Henriquez N, Toloza EM, Khalil F, et al. Extensive plastic bronchitis: etiology of a rare condition. $J$ Thorac Dis 2016; 8: E961-E965.

24 Feray S, Mora P, Decavele M, et al. Plastic bronchitis: an unusual complication of acute chest syndrome in adult. Respir Med Case Rep 2017; 21: 93-95.

25 Cox-Ganser JM, Burchfiel CM, Fekedulegn D, et al. Silicosis in lymph nodes: the canary in the miner? J Occup Environ Med 2009; 51: 164-169.

26 Caruthers RL, Kempa M, Loo A, et al.. Demographic characteristics and estimated prevalence of Fontan-associated plastic bronchitis. Pediatr Cardiol 2013; 34: 256-261.

27 Watanabe K, Ishida T, Sugawara A, et al. An adult case of plastic bronchitis. Intern Med 2008; 47: 1549.

28 Habib SA, Vasko RC, Badawy J, et al. Plastic bronchitis in an AIDS patient with pulmonary Kaposi sarcoma. Case Rep Pulmonol 2018; 2018: 1-5.

29 Irandost $\mathrm{M}$, Mohamed $\mathrm{H}$, Bhamrah $\mathrm{P}$, et al. A rare case of plastic bronchitis after tumor debulking and radiation treatment of endobronchial renal cell metastasis. Chest 2020; 158: A1921.

30 Schmitz LM, Rihawi M. Plastic bronchitis: a complication of myocardial revascularization to the editor. Am J Respir Crit Care Med 2012; 185: 896-897.

31 Stoddart A, Dincer HE, Iber C, et al. Chyloptysis causing plastic bronchitis. Respir Med Case Rep 2014; 13: 4-6.

32 Eberlein M, Parekh K, Hansdottir S, et al. Plastic bronchitis complicating primary graft dysfunction after lung transplantation. Ann Thorac Surg 2014; 98: 1849.

33 Savajiyani S, Shamsid-Deen N, Alalawi R. Medical image of the week: plastic bronchitis in an adult lung transplant patient. Southwest J Pulm Crit Care 2018; 17: 39-40.

34 Heath L, Ling S, Racz J, et al. Prospective, longitudinal study of plastic bronchitis cast pathology and responsiveness to tissue plasminogen activator. Pediatr Cardiol 2011; 32: 1182-1189.

35 Sheikh AY, Ahmadi-Kashani M, Mohindra V, et al. A rare case of plastic bronchitis in an adult patient after cardiopulmonary bypass. Ann Thorac Surg 2016; 101: 1176-1178.

36 Ponnuswamy A, Samani S, Gill P, et al. Unusual cause of recurrent bronchospasm - plastic bronchitis in an adult female. Chest 2020; 157: A14.

37 LaPelusa M, Hamid A, Ojeda-Damas D, et al. Coughing up casts: an adult case of plastic bronchitis. Chest 2019; 156: A1944-A1945.

38 Dori Y, Keller MS, Rome JJ, et al. Percutaneous lymphatic embolization of abnormal pulmonary lymphatic flow as treatment of plastic bronchitis in patients with congenital heart disease. Circulation 2016; 133:1160-1170.

39 Biko DM, DeWitt AG, Pinto EM, et al. MRI evaluation of lymphatic abnormalities in the neck and thorax after Fontan surgery: relationship with outcome. Radiology 2019; 291: 774-780.

40 Racz J, Mane G, Ford M, et al. Immunophenotyping and protein profiling of fontan-associated plastic bronchitis airway casts. Ann Am Thorac Soc 2013; 10: 98-107.

41 Irizarry GV, Cruz M, Fernandez R. An unusual presentation of chronic cough: plastic bronchitis and chyloptysis. Chest 2020; 158: A72.

42 Tomasulo CE, Chen JM, Smith CL, et al. Lymphatic disorders and management in patients with congenital heart disease. Ann Thorac Surg 2020; in press [https://doi.org/10.1016/j.athoracsur.2020.10.058].

43 Brogan TV, Finn LS, Pyskaty DJ, et al. Plastic bronchitis in children: a case series and review of the medical literature. Pediatr Pulmonol 2002; 34: 482-487. 
44 Rubin BK, Priftis KN, Schmidt HJ, et al. Secretory hyperresponsiveness and pulmonary mucus hypersecretion. Chest 2014; 146: 496-507.

45 Moser C, Nussbaum E, Cooper DM. Plastic bronchitis and the role of bronchoscopy in the acute chest syndrome of sickle cell disease. Chest 2001; 120: 608-613.

46 Nair LG, Kurtz CP. Lymphangiomatosis presenting with bronchial cast formation. Thorax 1996; 51: 765-766.

47 Sriratanaviriyakul N, Lam F, Morrissey BM, et al. Safety and clinical utility of flexible bronchoscopic cryoextraction in patients with non-neoplasm tracheobronchial obstruction. J Bronchol Interv Pulmonol 2015; 22: 288-293.

48 Dabo L, Qiyi Z, Jianwen Z, et al. Perioperative management of plastic bronchitis in children. Int J Pediatr Otorhinolaryngol 2010; 74: 15-21.

49 Preciado D, Verghese S, Choi S. Aggressive bronchoscopic management of plastic bronchitis. Int J Pediatr Otorhinolaryngol 2010; 74: 820-822.

50 Zahorec M, Kovacikova L, Martanovic P, et al. The use of high-frequency jet ventilation for removal of obstructing casts in patients with plastic bronchitis. Pediatr Crit Care Med 2009; 10: e34-e36.

51 Rubin BK. Plastic bronchitis. Clin Chest Med 2016; 37: 405-408.

52 Monagle K, Ryan A, Hepponstall M, et al. Inhalational use of antithrombotics in humans: review of the literature. Thromb Res 2015; 136: 1059-1066.

53 Robinson M, Smiley M, Kotha K, et al. Plastic bronchitis treated with topical tissue-type plasminogen activator and cryotherapy. Clin Pediatr (Phila) 2016; 55: 1171-1175.

54 Eason DE, Cox K, Moskowitz WB. Aerosolised heparin in the treatment of Fontan-related plastic bronchitis. Cardiol Young 2014; 24: 140-142.

55 Kovesi T, Gardin L. Bronchial cast. Pediatr Cardiol 2012; 33: 675-676.

56 Itkin MG, McCormack FX, Dori Y. Diagnosis and treatment of lymphatic plastic bronchitis in adults using advanced lymphatic imaging and percutaneous embolization. Ann Am Thorac Soc 2016; 13: 1689-1696.

57 Sheybani A, Gaba RC, Minocha J. Cerebral embolization of ethiodized oil following intranodal lymphangiography. Semin Intervent Radiol 2015; 32: 10-13.

58 Salman S, Shah A, Drinkwater DC, et al. Plastic bronchitis: is thoracic duct ligation a real surgical option? Ann Thorac Surg 2006; 81: 2281-2283.

59 Amsden GW. Anti-inflammatory effects of macrolides - an underappreciated benefit in the treatment of community-acquired respiratory tract infections and chronic inflammatory pulmonary conditions? $J$ Antimicrob Chemother 2005; 55: 10-21.

60 Schultz KD, Oermann CM. Treatment of cast bronchitis with low-dose oral azithromycin. Pediatr Pulmonol 2003; 35: 139-143.

61 Taveira-Dasilva AM, Hathaway O, Stylianou M, et al. Changes in lung function and chylous effusions in patients with lymphangioleiomyomatosis treated with sirolimus. Ann Intern Med 2011; 154: 797-805.

62 Wiles S, Mireles-Cabodevila E, Neuhofs S, et al. Endotracheal tube obstruction among patients mechanically ventilated for ARDS due to COVID-19: a case series. J Intensive Care Med 2021; 36: 604-611. 